\title{
El proceso de codificación del Derecho privado en Perú y Argentina
}

\section{Atilio Aníbal Alterini \\ Carlos A. Soto}

El proceso de codificación del Derecho privado en Perú y en Argentina se inició en forma paralela durante el siglo XIX.

Ambos países, hermanos en su esencia, tienen, además, un objetivo común que los acerca hoy todavía mucho más: lograr que sus sociedades disfruten de los beneficios que sólo las instituciones coherentes con la realidad y con los principios jurídicos pueden brindar, esto es, el bienestar social.

El fenómeno histórico de la codificación es de suma importancia para entender el proceso jurídico, por lo que realizaremos una breve reseña de este proceso en ambos países.

\section{La codificación en el Perú}

La codificación civil en el Perú comienza con el gobierno del Libertador Simón Bolívar, cuando en 1825 nombra una Comisión encargada de elaborar los códigos Civil y Criminal presidida por don Manuel Lorenzo de Vidaurre. Lamentablemente, esta Comisión nunca funcionó, pues -según el historiador peruano Jorge Basadre Grohman- el Perú no contaba aún con su Carta Política.

Posteriormente, mediante un Decreto del 22 de octubre de 1831, el Presidente Agustín Gamarra dispuso el establecimiento de una Comisión Codificadora General para que se encargara de elaborar el Código Civil. Ella tampoco funcionó.

La Constitución Política de 1834 estableció, en una de sus disposiciones transitorias, que anualmente la Corte Suprema en la apertura de 
sesión debía presentar al Congreso los proyectos de códigos de la legislación nacional, empezando por el Civil. El Presidente de la Corte Suprema don Manuel Lorenzo de Vidaurre asumió la redacción del Código Civil y entre agosto de 1834 y 1836 presentó su proyecto con una exposición de motivos, pero no fue tomado en cuenta.

En el año de 1836 aconteció un hecho histórico en la vida republicana del Perú: los departamentos de Arequipa, Ayacucho, Cusco y Puno se constituyeron en un Estado libre e independiente bajo la denominación de estado Sud-peruano y por decreto del 22 de junio de 1836 adoptaron el Código Civil boliviano, el cual ya se encontraba vigente desde 1830 y era copia fiel del Código Civil francés de 1804 . Unos meses después ocurrió otro hecho similar. El 11 de agosto de 1836 se erigieron en el estado Nor-peruano los departamentos de Lima, Libertad, Junín y Amazonas. Ese mismo año, el 28 de octubre, el Mariscal Andrés de Santa Cruz estableció la Confederación Perú-Boliviana, integrada por los estados Nor-peruano, Sur-peruano y Bolivia, y mediante decreto del $1^{\circ}$ de noviembre de 1836 dispuso la aplicación de los Códigos bolivianos, con ligeras modificaciones, al Estado Nor-peruano.

Ambos Códigos -Sur-peruano y Nor-peruano-, tuvieron una vida efímera, pues en 1838 el Presidente Luis José Orbegoso los derogó totalmente.

Ante la ausencia de norma civil vigente, nuevamente se aplicó la legislación española que era dispersa y confusa, además de alejada de la realidad sudamericana.

En 1845 el Presidente Ramón Castilla nombró una nueva Comisión Codificadora. Esta Comisión concluyó su trabajo en 1848. Así, el 22 de noviembre de 1850 Ramón Castilla promulgó los Códigos Civil y de Enjuiciamientos Civiles postergando su vigencia por el plazo de siete meses. En este lapso de vacatio legis se produjo la transmisión del mando supremo al general José Rufino Echenique, quien en mayo de 1851 solicitó la suspensión de la ley dictada por el Presidente Ramón Castilla. De esta manera, en junio de 1851 se ordenó la suspensión de la entrada en vigencia de ambos códigos y se nombró otra Comisión presidida por el jurista Andrés Martínez -esta Comisión trabajó sobre la base del proyecto de 1847-1848- y por fin el 29 de diciembre de 1851 se promulgaron los Códigos Civil y de Enjuiciamientos Civiles, entrando en vigencia el 29 de julio de 1852. Este Código Civil recibió una marcada influencia del Código Civil francés de 1804. 
La gran mayoría de autores se refieren al Código de 1852 como el primer Código Civil peruano, en virtud de su aplicación en toda la República. Sin embargo, si bien este Código tuvo gran importancia en la vida jurídica del Perú, pues estuvo vigente por más de ochenta años, no deben olvidarse los otros tres cuerpos legales reseñados.

Consecuentes con el cambio, los juristas peruanos de la primera etapa del siglo XX no tardaron en redactar otro Código Civil. De esta forma, el 30 de agosto de 1936 promulgaron un nuevo Código Civil y postergaron su vigencia hasta el 14 de noviembre del mismo año. Sus fuentes principales -según las actas de la Comisión- fueron los Códigos Civiles de Francia, Argentina, Alemania, Suiza y Brasil.

Posteriormente, en 1965, la comunidad jurídica peruana propugnó el estudio y revisión del Código Civil de 1936. En esta perspectiva, se creó una Comisión Reformadora que terminó elaborando el actual Código de 1984, constituyendo una fuente importante en su redacción el nuevo Código Civil italiano de 1942. El vigente Código Civil fue promulgado el 24 de julio de 1984 y se encuentra vigente desde el 14 de noviembre del mismo año.

En síntesis, el Perú ha contado con seis códigos civiles todos, excepto uno, vigentes luego de su promulgación.

Sin embargo, con inmediata posterioridad a la entrada en vigor del nuevo Código Civil de 1984, sus propios autores - entre otros juristas - plantearon la necesidad de reformar algunos de sus artículos e, inclusive algunas de sus instituciones, con la finalidad de corregir o enmendar errores. En realidad, al día siguiente de su promulgación, los autores del Código ya exigían enmiendas, en razón de que la Comisión Revisora del Proyecto modificó (o simplemente no acogió) algunos planteamientos de los juristas integrantes de la Comisión Reformadora. Tal es el caso - por mencionar uno solo - del autor del Libro Primero de Derecho de las Personas del Código Civil, doctor Carlos Fernández Sessarego, quien ha escrito que "[...] la reforma del Libro Primero del Código Civil quedó planteada al día siguiente de su promulgación. Preocupaba [...] que algunos planteamientos del ponente del Libro Primero del Código Civil, no obstante su probada bondad, no fueran acogidos por la Comisión Revisora del Proyecto de Código Civil, contrariando la opinión mayoritaria de la doctrina o de la legislación comparada que avalaba tales propuestas". 
Vemos en esta actitud que una de las características ejemplares en la comunidad jurídica peruana es su inquietud por el cambio coherente y sistemático. En este sentido, el Perú se encuentra actualmente en un proceso de reforma de sus Códigos Civil y de Comercio.

En la difusión del Código Civil de 1984 y en el planteamiento de reformas urgentes tuvo una destacada participación el doctor Carlos Fernández Sessarego, quien en su condición de Director del Centro de Investigaciones de la Universidad de Lima convocó a partir de 1992 a todos los profesores de derecho civil para trabajar en el estudio y revisión del Código Civil de 1984 con la finalidad de elaborar un Proyecto de enmiendas. Este trabajo culminó en 1994 y en ese año el profesor Fernández Sessarego entregó al entonces Presidente del Congreso Constituyente doctor Carlos Torres y Torres Lara el Proyecto de enmiendas que habían elaborado los juristas convocados. Dicho proyecto se publicó el 07 de enero de 1995 en el Diario Oficial «El Peruano».

Sin lugar a dudas, otro motor que impulsó la reforma del Código Civil de 1984 fue el "gran cambio" cuantitativo y cualitativo de las estructuras económicas, sociales y políticas. Igualmente, en la realidad peruana la estructura jurídica del sistema peruano ha sido objeto de cambios debido a que surgieron nuevas formas de contratación; de un nuevo sistema de contratación: la contratación en masa o predispuesta; la aparición de un nuevo elemento en la sociedad: el consumidor; el actual rol de la empresa en producción y distribución de bienes y servicios; la unificación de las obligaciones y contratos; entre otros temas de gran importancia. Todo ello en adición a las variadas reformas legislativas en distintas áreas del derecho peruano, específicamente desde 1992.

Indiscutiblemente, un hito de enorme importancia en el Perú lo constituye la promulgación de una nueva Constitución Política en 1993, la cual contempla un sistema económico y político distinto y, que en forma expresa rechaza la intervención del Estado en las relaciones contractuales. En efecto, el artículo $62^{\circ}$ de la Constitución Política peruana señala:

«La libertad de contratar garantiza que las partes puedan pactar válidamente según las normas vigentes al tiempo del contrato. Los términos contractuales no pueden ser modificados por leyes $\mathbf{u}$ otras disposiciones de cualquier clase. Los conflictos derivados de la relación contrac- 
tual sólo se solucionan en la vía arbitral o en la vía judicial, según los mecanismos de protección previstos en el contrato o contemplados en la ley.

Mediante contratos-ley, el Estado puede establecer garantías y otorgar seguridades. No pueden ser modificados legislativamente, sin perjuicio de la protección a que se refiere el párrafo precedente».

Los sucesos señalados motivaron que en el medio político-jurídico peruano se gestara un movimiento destinado a reformar el Código Civil de 1984, a fin de evitar que se convierta en un código de letra muerta.

Somos partidarios de considerar que cuando los presupuestos sociales, económicos, políticos, tecnológicos e ideológicos se transforman, se torna necesaria una reforma de las estructuras jurídicas para evitar el divorcio entre ley y realidad. Es necesario también desechar normas obsoletas, ineficaces e inútiles. Por el contrario, esa realidad debe sustituirse por leyes modernas, vigentes, ágiles y eficaces que brinden seguridad a sus destinatarios, garanticen el libre desenvolvimiento de sus actividades económicas y se conviertan en verdaderos mecanismos de desarrollo y progreso. Negar la necesidad de la reforma equivale a ponernos una venda en los ojos o, como en la alegoría de la caverna de Platón, observaríamos la "realidad» en las sombras que de ella arrojan las instituciones infectadas de dogmatismos caducos, lo que a todas luces no sólo es ineficiente, sino peligroso, ya que crea los tan temidos «mercados negros».

En este orden de ideas no podemos olvidar que la sociedad está en constante evolución y, siendo la codificación el vehículo de manifestación más idóneo del derecho, es necesario un remozamiento, una actualización, una adecuación de las instituciones jurídicas con la realidad.

Para algunos autores, la codificación iniciada con el Emperador Justiniano en su Corpus Juris Civile -cuya máxima expresión la constituye el Código Napoleón de 1804- parece haber llegado a su fin debido a la revolución y los cambios ideológicos, a la incesante transformación industrial y la creciente producción en masa. Ciertamente, aunque la respetamos, nosotros no participamos de esta tesis, pues si bien la tecnología -mediante los soportes electrónicos- viene sustituyendo al libro, no es totalmente cierto que con ello se produzca la desaparición de los códigos o cuerpos de leyes sistemáticos. 
Por todos los fundamentos indicados, el 22 de noviembre de 1994 el Congreso Constituyente Democrático dictó la Ley No 26394 creando una Comisión denominada Comisión especial encargada de elaborar el Anteproyecto de Ley de Reforma del Código Civil. Posteriormente, el 22 de octubre de 1996 el Congreso de la República publicó la Ley No 26673, reconstituyendo la Comisión de Reforma del Código Civil y ampliando el número de sus miembros.

En la actualidad, los miembros de la Comisión de Reforma del Código Civil son los Congresistas doctores Jorge Muñiz Zíches, Oscar Medelius Rodríguez, Jorge Avendaño Valdez y Lourdes Flores Nano; y los juristas Manuel de la Puente y Lavalle, Fernando de Trazegnies Granda, Carlos Fernández Sessarego, Carlos Cárdenas Quirós, Augusto Ferrero Costa, Guillermo Lohmann Luca de Tena, Guillermo Velaochaga Miranda y Fernando Vidal Ramírez. La Secretaría Técnica se encuentra a cargo de los doctores Silvana Migliori Figueroa, Fernando Zambrano Ortíz y del suscrito Carlos Alberto Soto Coaguila.

La Comisión eligió como Presidente Honorario a uno de los más representativos juristas del medio peruano, el doctor Manuel de la Puente y Lavalle.

Pese a su corta edad, el Código Civil peruano - según los juristas peruanos - exige una reforma, pero ¿̇cuáles son las razones para reformarlo?. El Presidente de la Comisión de Reforma del Código Civil Peruano, doctor Jorge Muñiz Zíches, en el marco del I Congreso Nacional de Derecho Civil sobre la Reforma del Código Civil Peruano planteó las razones que motivaron la necesidad de revisar el Código Civil con la finalidad de proponerle reformas urgentes. Las razones son:

a) Se han producido diversos avances en la ciencia y en la tecnología como la reproducción humana asistida, la fecundación in vitro, el proyecto genoma humano, los transplantes de órganos, la contratación computarizada, entre otros.

b) Se han producido diversas modificaciones parciales del Código por medio de otros textos legales.

c) Resulta necesario adecuar las normas del Código Civil a la Constitución Política de 1993, caracterizada esta última por la relativización y flexibilización de los derechos económicos y sociales, el debilitamiento del Estado en cuanto a su función en la actividad produc- 
tiva y el giro de la economía hacia una opción de libre mercado. Igualmente, es imprescindible concordar los postulados de la Constitución de 1993 con las del Código Civil. Un ejemplo es el artículo $62^{\circ}$ de nuestra Carta Política que regula lo que en doctrina se conoce como la "santidad de los contratos" en contradicción con el artículo $1355^{\circ}$ del Código Civil que permite la intervención del Estado en las relaciones contractuales.

d) Se han detectado una serie de defectos en las figuras e instituciones del Código.

e) Existe la necesidad de regular una serie de contratos modernos, que hoy en día son de uso frecuente en nuestro país.

f) La unificación de las reglas del derecho civil y del derecho comercial en un solo texto de derecho privado, de acuerdo a la nueva tendencia en el derecho moderno. Esta unificación se inició con el Código de 1984, pero no fue completa. La razón de la unificación radica en la imposibilidad teórica y práctica de seguir dividiendo a los actos jurídicos, obligaciones y contratos en civiles y mercantiles. Por lo tanto, se requiere que el Código Civil recoja y regule todas las reglas aplicables a los actos civiles y mercantiles.

Los codificadores peruanos, conscientes de una reforma al Código Civil, se preguntaron si la reforma debía ser total o parcial. Frente a ello, la Comisión Peruana ha decidido no alterar la estructura del actual Código ni reformarlo en su integridad, sino proponer modificaciones necesarias.

Consideramos importante aclarar que las reformas necesarias y urgentes no constituyen simples maquillajes, tampoco implican deshacerse del Código Civil de 1984 y elaborar uno nuevo. La decisión de la Comisión de proponer modificaciones urgentes y necesarias al Código Civil de 1984 con el objeto de dotar al Perú de un Código Civil dinámico, funcional y eficaz, es unánime.

En esta medida, somos conscientes de que las instituciones no envejecen, sino que son sus contenidos, funciones y dinámica los que cambian.

Desde su instalación, la Comisión de Reforma del Perú ha desplegado todas sus fuerzas para lograr el objetivo propuesto. En esta perspectiva, ha creado Subcomisiones de trabajo que presentan al pleno de la Comisión propuestas de reforma a introducirse en cada uno de los 
Libros del Código Civil, incluyéndose el Título Preliminar o Parte General.

Hasta la fecha se han aprobado las modificaciones al Título Preliminar, al Libro de Derecho de las Personas, al Libro del Acto Jurídico, la Sección de la Parte General de los Contratos y actualmente se vienen aprobando las modificaciones al Libro de los Derechos Reales.

Expresábamos que una de las razones para reformar el Código Civil peruano de 1984 era la tendencia unificadora de las obligaciones y contratos civiles y mercantiles en razón que es muy complicado -por no decir imposible- distinguir en la práctica unos de otros. En este sentido, la doctrina y la realidad exigen la unificación de ambos textos legales o la incorporación de estas figuras jurídicas a los códigos civiles.

Existen importantes antecedentes legislativos de la unificación civil y comercial. Un reciente proyecto unificador es el Proyecto de Código Civil de Argentina de 1998, pero no es el primer intento de unificar los Códigos Civil y Comercial en Argentina, pues existen otros anteriores; sin embargo, el mencionado proyecto argentino que consta de 2532 artículos es muy novedoso, pues no solo unifica los Códigos Civil y Comercial, sino que incorpora nuevas figuras jurídicas que han venido surgiendo en la vida diaria, como los denominados contratos modernos y la contratación masiva, encontrándose también en este proyecto la Teoría General de Títulos Valores y los Contratos Asociativos.

En el Perú, la corriente unificadora también responde a una necesidad. En efecto, mediante la Ley $\mathrm{N}^{\circ} 26595$ se creó una Comisión especial encargada de elaborar el proyecto de Código de Comercio. No obstante, esta Comisión fue facultada para presentar un proyecto de Código de Comercio o un texto que lo sustituya.

La Comisión de Reforma del Código de Comercio decidió optar por una técnica legislativa distinta, tomando como sustento de ello la realidad comercial. Recordemos que el vigente Código de Comercio data de 1902 y a los noventisiete años de vigencia ha sufrido modificaciones sustanciales ocasionando una desmembración de su contenido en leyes especiales, lo cual ha generado que no quede casi nada del texto original del Código. El vetusto Código de Comercio hoy en día ya no tiene sentido y, podríamos afirmar que se encuentra muerto antes de ser derogado.

La decisión de la Comisión de Reforma del Código de Comercio del Perú ha sido la de redactar una Ley marco del empresariado toman- 
do como categorías centrales a la empresa y al empresario, que hoy son los ejes de la economía.

Esta ley marco del empresariado intenta ser la base legal de toda la actividad empresarial, comprendiéndose dentro de ésta a la Ley General de Sociedades, la Ley General de Cooperativas, las asociaciones civiles, las fundaciones y otras formas de organización individual o colectiva.

Los trabajos de esta Comisión se han culminado exitosamente y, en el mes de abril de 1999 se ha entregado a la Comisión Permanente del Congreso de la República los anteproyectos de la Ley marco del empresariado, la Ley del Contrato de Seguro y la Ley de la Navegación y el Comercio Marítimo para su aprobación y correspondiente publicación.

Con estas propuestas legislativas se derogaría el Código de Comercio y todo lo relativo a las obligaciones y contratos mercantiles contemplados en el Código de Comercio deberá ser recogido en las reformas al Código Civil de 1984.

El Perú no ha optado por un Código único Civil y Comercial como la Argentina, pues considera que no es necesaria la dación de un nuevo Código de Comercio y menos la fusión de los Códigos Civil y Comercial, basta la incorporación de las obligaciones, actos jurídicos y contratos que regula el Código de Comercio de 1902 al Código Civil peruano. En cuanto a las áreas especiales como el derecho de seguros y el derecho marítimo se ha optado por leyes especiales.

No debemos olvidar que en el Código Civil de 1984 el Perú mercantilizó de alguna manera el viejo tronco del sistema jurídico. El artículo $2112^{\circ}$ derogó cinco contratos contenidos en el Código de Comercio: los de compraventa, permuta, mutuo, depósito y fianza mercantil. El artículo $1353^{\circ}$ sujetó a todos los contratos, inclusive los innominados, a las reglas generales del Código Civil. El artículo $196^{\circ}$ presumió la onerosidad de las garantías sobre determinados créditos. El artículo $1055^{\circ}$ admitió, junto a la entrega material, la entrega jurídica de la prenda. El artículo $1382^{\circ}$ estableció la obligatoriedad de la oferta. El artículo $1758^{\circ}$ remitió a la habitualidad del ejercicio profesional en el contrato de prestación de servicios para presumir la aceptación entre ausentes, entre otros temas.

Recientemente, con fecha 19 de octubre de 1999 el Congreso de la República del P'erú ha delegado en la Comisión Permanente del Congreso la facultad de aprobar la Ley Marco del Empresariado, la Ley del 
Contrato de Seguro y la Ley de Navegación y Comercio Marítimo, otorgándole al efecto 180 días.

\section{Un nuevo código civil para Argentina: el proyecto de 1998}

En Argentina, el 25 de setiembre de 1869 se promulgó el Código Civil por Ley No 340, estableciéndose en esta misma ley "que el Código Civil redactado por el doctor Vélez Sarsfield, regiría desde el $1^{\circ}$ de enero de 1871". No tardaron los juristas argentinos en poner en marcha una reforma al Código Civil. Así, en 1926 Juan Antonio Bibiloni preparó el Anteproyecto de 1926 y una Comisión especial redactó el Proyecto de 1936. Pero esas iniciativas no fructificaron, tanto que el profesor Guillermo Borda llegó a decir que se convirtieron en "polvo, ceniza, nada».

En 1950 fue impulsado en Argentina otro proyecto de reformas, que culminó con el Anteproyecto de 1954, obra dirigida por el profesor Jorge Joaquín Llambías, pero fue frustrado enseguida por uno de los tantos episodios de la intolerancia política en este siglo tumultuoso. Ni siquiera fue publicado, sólo circuló entre algunos pocos profesores en una edición limitada y precaria hecha en rotaprint, y recién en 1967 la Universidad Nacional de Tucumán le dio difusión con forma de libro.

En materia mercantil, según explica Carlos Torres y Torres Lara, «el comercio varía día a día y las necesidades económicas así lo exigen», pero «no hay tiempo para dictar nuevos Códigos, pues mientras las Comisiones estudian cómo lograr una nueva codificación, el Código sigue siendo modificado por partes». Los Códigos de Comercio, en definitiva, «quedan literalmente descuartizados». En concordancia a ello, en la Introducción a las Notas Explicativas del Proyecto argentino de Código único de 1987 fue señalado que «lo que hoy se conoce como Código de Comercio es, principalmente, la presentación conjunta de una variedad de leyes especiales». Esto sucedió tanto en Argentina como en Perú.

En Argentina se intentó una y otra vez reformar los Códigos del Derecho Privado, con la idea básica de unificarlos y de modernizarlos bajo la forma del denominado Derecho Privado o Derecho Privado Patrimonial. $Y$ es que en el Derecho vivo se ha producido la 
comercialización del Derecho Civil -antes bien que la civilización del Derecho Comercial- lo cual deriva de la masificación de la nueva socie$\mathrm{dad}$, todos cuyos integrantes participan en actividades mercantiles. Al respecto señalaba con razón Ripert que una persona que no adquiera ningún inmueble puede pasar la vida sin acudir a una escribanía, pero no puede dejar de acudir, hasta cotidianamente, a un banco.

Para determinar si la unificación que se ha producido es una tarea útil es necesario explorar si, en un determinado sistema jurídico, se dan los indicadores que destaca Mario Rotondi. Ellos son la incorporación al Código Civil de los principios propios de los contratos comerciales por ejemplo: la doctrina de la apariencia, la fuerza jurígena de los usos, la interpretación conforme a la buena fe-probidad, la mora automática, la cláusula resolutoria tácita, el anatocismo, el sometimiento del concurso de los no comerciantes a igual procedimiento que el aplicado a los comerciantes y la sujeción al juez mercantil. Los particularismos de la legislación de la navegación. La generalización de los títulos valores. Todos esos indicadores se dan claramente en Argentina, en especial porque su Código Civil recogió la mayoría de los principios mercantiles a través de la reforma que le introdujo la Ley $\mathrm{N}^{\circ} 17.711$ en el año 1968.

En Argentina, en 1986, la Cámara de Diputados de la nación creó una Comisión Especial de Unificación Legislativa Civil y Comercial, la cual encomendó la redacción del correspondiente proyecto a una Comisión Especial Honoraria. El Proyecto de Código Único fue sancionado por esa Cámara en 1987, y varios años después por el Senado, que no le introdujo ninguna modificación. Se convirtió así en ley, pero fue íntegramente vetada por el Poder Ejecutivo.

En 1992 la Cámara de Diputados de la nación designó una Comisión Honoraria, que preparó el denominado Proyecto de la Comisión Federal de esa Cámara, sancionándolo en 1993 y remitiéndolo al Senado, pero éste no lo trató. En su redacción fueron tenidos «especialmente en cuenta los proyectos de reforma del Código Civil realizados hasta la fecha, entre ellos el de Unificación de la Legislación Civil y Comercial de 1987».

También en 1992 el Poder Ejecutivo Nacional designó otra Comisión Honoraria, la cual elaboró el denominado Proyecto del Poder Ejecutivo Nacional de 1993. Fue enviado al Senado, pero tampoco recibió tratamiento alguno. 
Luego, en 1995, el Poder Ejecutivo designó otra Comisión Honoraria, a la que encargó «el estudio de las reformas que considere necesarias a fin de dar conclusión a un texto homogéneo en todo el referido cuerpo legal», a cuyo fin le dio el cometido de "proyectar la unificación del Derecho Privado" y "su reforma y actualización, de manera integral», en consonancia con los dos proyectos de unificación de la legislación civil y comercial de 1993; así como incorporar «las instituciones que se consideren convenientes para acompañar el proceso de modernización que ha emprendido el país», atendiendo a la reforma de la Constitución Nacional de 1994, y a los Tratados con jerarquía constitucional (artículo $75^{\circ}$, inciso 22, Constitución Nacional argentina), en cuanto contienen «disposiciones relativas a materias de los Derechos civil y comercial». El 8 de julio de 1999 el Presidente de la Nación remitió ese proyecto a la Cámara de Diputados, donde actualmente tramita en sede de la Comisión de Legislación General.

Los firmantes de este último proyecto son los profesores doctores Héctor Alegría, Jorge Horacio Alterini, María Josefa Méndez Costa, Julio César Rivera, Horacio Roitman y el suscrito Atilio Aníbal Alterini, quienes han colaborado conjuntamente con los integrantes de la Comisión de Reforma del Código Civil Peruano en la elaboración de la obra que presentamos.

¿Qué perspectivas tiene el Proyecto argentino de 1998?. Cualquier observador objetivo puede advertir el alto interés que ha despertado en el breve tiempo transcurrido desde su presentación al Ministerio de Justicia en el mes de diciembre de 1998.

El mayor entusiasmo proviene de los más jóvenes, para quienes resulta intolerable que continúen siendo operativas normas que fueron adecuadas para el siglo XIX, pero que son incompatibles con la reforma constitucional argentina de 1994, con los tratados dotados de jerarquía constitucional, y con las exigencias de la economía de mercado. El Código de Comercio argentino pone todavía el acento en la responsabilidad resultante del transporte en "falúas" y en "canoas" (artículo $206^{\circ}$ ); el sistema se ocupa del agente (artículo $1151^{\circ}$, Código Civil), quien habría viajado a caballo o en barco, y de la celebración del contrato por correspondencia (nota a los artículos $1150^{\circ}$ al $1154^{\circ}$, Código Civil); el Código Civil argentino no menciona a las máquinas ni en el texto ni en las notas del Título en el que trata de los hechos ilícitos, en tanto aplica unos sesenta artículos a regular la administración de la 
tutela, y diecisiete a legislar sobre la búsqueda y adquisición de tesoros. El Código de Comercio alude al mensajero (artículo $215^{\circ}$ ), y asume como novedad tecnológica a la correspondencia telegráfica (artículo $214^{\circ}$; el telégrafo había sido patentado en 1840 ), porque lo normal en el sistema era comunicarse mediante el correo (artículo $246^{\circ}$ ), lo cual podía determinar que hubiera demoras notables en la transmisión de la manifestación de la voluntad (artículo 236 ${ }^{\circ}$ ).

Todo ello es congruente con la época de sanción del Código Civil argentino: en 1869 no habían luz eléctrica, teléfonos, fonógrafos, linotipia, lapiceras fuente, automóviles propulsados a nafta o a diesel, neumáticos de caucho, películas flexibles para fotografía, cine, submarinos; no se cultivaban bacterias; no se conocía la causa de la tuberculosis ni la del tétanos, ni los rayos X, ni los virus filtrables; no había sido fundado el psicoanálisis, ni se había descubierto la radiación del átomo de uranio.

Pero, evidentemente, las cosas han cambiado de modo radical, primero por el auge de la sociedad industrial que los viejos Códigos no tomaron en cuenta y, en la segunda mitad de este siglo, por la irrupción de la era postindustrial o tecnológica, así como por el reciente - pero avasallador- fenómeno de la globalización.

Argentina está en situación de tener un Código Civil moderno, a compás de los tiempos actuales, que sea -además- el primero del siglo XXI. Pero hay que superar escollos importantes, que existen en ese país, pero de ninguna manera son exclusivos ni excluyentes. Es sugestivo que en todo sistema en el que se intenta modificar la legislación aparezca un cortejo más o menos semejante de contradictores.

Están, por una parte, los misoneístas, los que tienen miedo al cambio, algunos de ellos actuando como reformistas en el discurso y como gatopardistas en la acción. Una de sus técnicas es demorar los hechos, sobre lo cual en Argentina hay mala experiencia. El Proyecto de Bibiloni fue analizado durante cuatro años, en especial por la Sección de Derecho Civil del Instituto Argentino de Estudios Legislativos de la Federación Argentina de Colegios de Abogados -que publicó varios volúmenes con las actas de las deliberaciones- y aunque, como afirmó el profesor Lafaille en un discurso pronunciado en el II Congreso Nacional de Derecho Civil (Córdoba, 1939), era en síntesis "el Código puesto al día, según nuestra doctrina y nuestra jurisprudencia», no recibió siquiera tratamiento legislativo. El Proyecto de Código Único de 1987 
estuvo por años en el Senado, opinó quien quiso, pero esa Cámara no le introdujo ninguna modificación.

Están los que sienten afectados sus intereses, porque sus libros perderán actualidad, porque tendrán que seguir estudiando y trabajando, y se resisten entonces al progreso legislativo. Alguien los considera partícipes necesarios de una "conspiración de los editores".

Están los desinformados, que creen que por conocer algunas obras de áreas especiales y la legislación de unos pocos países son expertos en todo, y se sienten habilitados para cuestionar todo.

Están los admiradores del derrumbe, los que tienen como lema "mejor que construir es destruir", a quienes les es indiferente la construcción de un edificio pero quedan extasiados ante su destrucción.

Están los sofistas, que disponen de todo el cortejo imaginable de argumentos falsos. Suelen abusar de la petición de principio, y predican enfáticamente por su sola voz, sin haber hecho análisis alguno, "esta solución es mala». O utilizan la mutatio elenchi, argumentando sobre lo que no está en discusión. $O$ aplican la falsa generalización, extendiendo al todo la crítica a lo singular.

Están también los admiradores del dictador Mustafá Kemal Ataturk, quienes creen que como en Turquía en los años veinte, se puede imponer a la sociedad el Código que se le ocurra a cualquiera; es decir, están los que piensan que sólo es admisible su propio Código, el que a ellos les gusta. Es muy grave que se olviden que un Código de Derecho Privado es un pacto social de la vida ciudadana, un resultado del consenso que atañe al «Derecho común, esto es -diría Alfredo Orgaz-, al Derecho que interesa inmediatamente a la generalidad de los hombres, sin distinciones de actividades y profesiones".

Pero los más temibles son los académicos de los que se ocupó Umberto Eco -en el ensayo "De Pathmos a Salamanca", contenido en su libro Appocalittici e integrati-, que actúan en función de Profetas del Apocalipsis, como el sabio de Salamanca. El sabio de Salamanca, profesor en la Universidad homónima a fines del siglo XV, era experto en astronomía y en geografía, y conocía todo lo que enseñaban los textos antiguos acerca del modelo de Ptolomeo. Pero Colón demostró que se podía llegar al Levante por el Poniente, por lo cual perdieron valor los libros de astronomía y de geografía de los que el sabio de Salamanca era el profeta y el difusor autorizado, y los nuevos técnicos de la Tierra vinieron a ser los navegantes, los exploradores, los que tenían capaci- 
dad para adaptarse a la nueva visión de las cosas. Frente a esa novedad, al sabio de Salamanca se le presentaron dos alternativas. Una, convertirse en Profeta del Apocalipsis y, sin poder negar que América existía, sostener que su descubrimiento era moral y culturalmente negativo, que era malo que América existiera, que resultarían graves daños para la humanidad, y gritar a la gente «a dónde iremos a parar». Otra alternativa fue convertirse en experto en la nueva realidad, y - textualmente de Eco - seguir siendo «maestro de vida para millares de discípulos».

No hay dudas de que lo deseable es que tales académicos asuman que se han producido transformaciones, y se pongan rápidamente al día, porque - como señalaba Josserand - o el Derecho se adecua a los hechos, o los hechos prescinden del Derecho. Y prescinden también de sus operadores.

De nuevo, por última vez, la misma pregunta: ¿qué perspectivas tiene el proyecto argentino de Código Civil de 1998?. Depende de la racionalidad de los juristas, de la medida en que los legisladores comprendan la realidad social y sus necesidades, del criterio de los intelectuales a los que la comunidad respeta académicamente.

\section{El acta de Arequipa}

En la ciudad de Arequipa, en el mes de agosto se llevó a cabo el histórico Encuentro de las Comisiones Reformadoras de cuatro países que vienen reformando sus Códigos Civiles, nos referimos a Perú, Argentina, Bolivia y Puerto Rico, quienes se reunieron en el marco del «II Congreso Internacional de Derecho Civil». En este importante evento las cuatro Comisiones referidas suscribieron el 7 de agosto lo que se denominó «El Acta de Arequipa», la que por su importancia transcribimos en el presente trabajo.

«Las Comisiones de Reforma de los Códigos Civiles de Argentina, Bolivia, Perú y Puerto Rico, reunidas en el marco del II Congreso Internacional de Derecho Civil denominado "Encuentro de las Comisiones de Reforma de los Códigos Civiles de Perú y Argentina" y "15 años del Código Civil Peruano y su Proceso de Reforma" en la ciudad de Arequipa - Perú, realizado entre el 04 y 07 de agosto de 1999, declaran: 
I. Que la codificación es el método más adecuado para la expresión del derecho privado, como lo demuestra el vasto movimiento codificador que se aprecia en todos los sistemas jurídicos;

II. Que la vigencia innegable de ese método exige la puesta al día de los códigos existentes, para adecuarlos a las nuevas realidades sociales, culturales, políticas, económicas y tecnológicas;

III. Que la internacionalización de las relaciones jurídico-económicas y el proceso de globalización imponen perseguir la armonización de las codificaciones en todo cuanto sea posible, incluso en sus lineamientos generales de técnica legislativa, respetando los particularismos de cada sociedad;

IV. Que la armonización en sectores relevantes del derecho privado es posible en América Latina, por la pertenencia a la familia romano-germánica, lo que constituye un indudable factor de identidad cultural;

V. Que la redacción de los nuevos Códigos o la revisión de los existentes, se ha de hacer sobre la base de algunos principios fundamentales:

a) Su adecuación a la Constitución de cada Estado y a la eventual pertenencia a comunidades de integración;

b) La recepción y regulación de los derechos humanos, de modo que los códigos sigan siendo la fuente mas próxima y efectiva de la protección de la persona;

c) La protección de los débiles y el respeto de la autonomía de la voluntad en las relaciones entre sujetos con equivalente poder de negociación;

d) Reformular los principios de la contratación, los procesos de informatización y de circulación de los bienes, para adecuarlos a necesidades modernas y para contemplar instituciones comunes al desarrollo económico de los pueblos, con herramientas dinámicas y actualizadas, todo ello en un marco de equidad;

e) El reconocimiento de las nuevas formas de propiedad;

f) El establecimiento de un sistema equilibrado de responsabilidad civil;

g) El fortalecimiento de la familia;

h) El respeto por las minorías; 
i) El reconocimiento de la identidad cultural de las poblaciones indígenas;

j) El facilitamiento, a través de la legislación interna, de la integración regional.

VI. Que las comisiones de Argentina, Bolivia, Perú y Puerto Rico se comprometen a:

a) Estar en comunicación permanente para intercambiar opiniones e información;

b) Propiciar la difusión de sus trabajos;

c) Recomendar la rápida difusión de sus tareas y la sanción de los códigos o reformas en función de los principios expuestos [...]». 